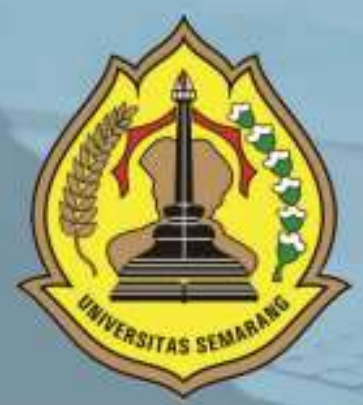

PENGARUH WORK FAMILY CONFLICT, STRES KERJA DAN KEPEMIMPINAN TERHADAP TURNOVER INTENTION KARYAWAN (STUDI PADA SELURUH KARYAWAN BAGIAN PLANNING PRODUCTION AND INVENTORY CONTROL PT. PARKLAND WORLD INDONESIA JEPARA

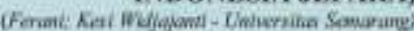

STUDI SOFT SKILL LULUSAN PENDIDIKAN KEJURUAN DI TEMPAT KERJA

Whort-Chiversikio Semorang

ANALISIS IINGKUNGAN INTERNAL DAN EKSTERNAL, PADA UKM PREMIUM PLUS LAUNDRY CABANG MULAWARMAN SEMARANG

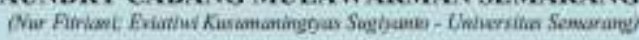

FAKTOR-FAKTOR YANG MEMPENGARUHI PERTIMBANGAN TINGKAT MATERIALITAS AUDIT

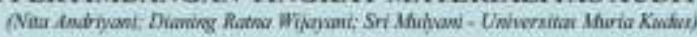

MANAJEMEN LABA DAN FAKTOR-FAKTOR YANG MEMPENGARUHINYA (STUDI EMPIRIS PADA PERUSAHAN MANUFAKTUR DI BEI)

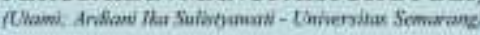

PENDAPATAN ASLI DAERAH, DANA PERIMBANGAN, DAN SISA LEBIH PEMBIAYAAN ANGGARAN TERHADAP PENGALOKASIAN BELANJA MODAL: STUDI PADA KABUPATEN/KOTA DI PROVINSI JAWA TENGAH

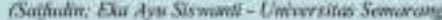

PERSEPSI PENGGUNA JASA TRANS JATENG TERHADAP KUALITAS PELAYANAN ANGKUTAN AGLOMERASI PERKOTAAN TRANS

JATENG

(Studi Kasus Trans Jateng Koridor I Semarang (Tawang) - Bawen)

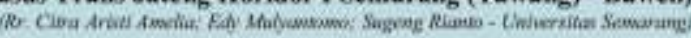

WORTHLESSNESS IS A POWER: MENGAPA ORANG BERSEDIA MENARUH UANG DI APLIKASI GO-PAY

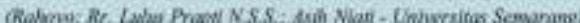

ANALISIS PENGARUH KUALITAS PRODUK, PERSEPSI HARGA, DAN PROMOSI TERHADAP KEPUTUSAN PEMBEIIAN WELLBLUE AL KALINE WATER PITCHER

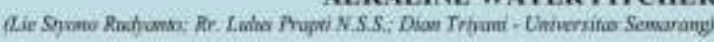

STRATEGI PEMASARAN UNTUK MENINGKATKAN VOLUME PENJUALAN (STUDI KASUS PADA SHOFA CATERING)

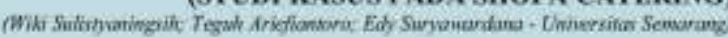

PENGARUH CITRA MEREK, PERSEPSI HARGA, DAN KUALITAS PRODUK TERHADAP KEPUTUSAN PEMBELIAN SEPATU OLAH RAGA MEREK ADIDAS

(Studi di Kota Semarang)

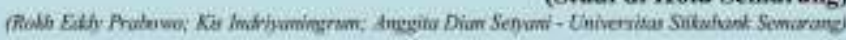

PENGARUH KEMUDAHAN TERHADAP KEPUTUSAN MENGGUNAKAN E-BANKING PADA BNI 46 KC KARANGAYU SEMARANG DENGAN MINAT NASABAH DAN KEPERCAYAAN SEBAGAI VARIABEL. MEDIASI

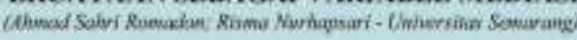

PENELITLAN KEBERLANGSUNGAN USAHA ARDANI INDONESIA SEBAGAI UMKM BERBASIS INDUSTRI KREATIF

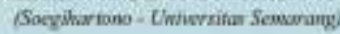

STRATEGI PELAYANAN BUS RAPID TRANSIT (BRT) TRANS SEMARANG

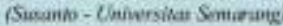

ANALISIS PENGARUH KEPEMIMPINAN, STRES KERJA, DAN LINGKUNGAN KERJA TERHADAP KINERJA KARYAWAN BAGIAN PRODUKSI SEWING PT. SAMWON BUSANA INDONESIA SEMARANG

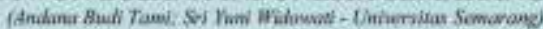




\section{DESKRIPSI}

Majalah IImiah Solusi Mengkaji

Masalah-Masalah Sosial,

Ekonomi dan Bisnis

\section{KETERANGAN TERBIT}

Terbit Pertama Kali Juli 2002

dan SelanjutnyaTerbit Tiga Bulan

Sekali (Januari, April, Juli dan

Oktober)

\section{PENERBIT}

Fakultas Ekonomi USM

\section{ALAMAT PENERBIT}

JL. Soekarno Hatta Semarang

Telp. 024-6702757 Fax. 024-6702272

\section{PENGELOLA}

Editor in Chief : Yohanes Suhardjo, SE, M.Si., Ak, CA Vice Editor Chief : Sugeng Rianto, SE, MM

Managing Editor: Edy Suryawardana, SE, MM

Secretary of Managing Editor : Asih Niati, SE, MM

Administration \& Circulation :

Citra Rizkiana, SE, MM

Layout \& Typesetting : M Burhan Hanif S.Kom, M.Kom

Board of Editors:

1. Prof. Dr. Ir. Kesi Widjajanti, SE, MM (USM)

2. Prof. Drs. Mohammad Nasir, Msi, Ph.D, AK. (USM)

3. Prof. Supramono SE, MBA, DBA (UKSW)

4. Prof. Drs. H. Imam Ghozali, M.Com, Akt, PhD (UNDIP)

5. Prof. Dr. Agus Suroso, MS (UNSOED)

6. Prof. Dr. Widodo, SE, M.Si (UNISSULA)

7. Prof. Dr. Dra. Sulastri, ME, M.Kom (UNSRI)

8. Dr. Ardiani Ika S, SE, MM, Ak, CA, CPA (USM)

\section{KATA PENGANTAR}

Sungguh merupakan kebahagiaan tersendiri bagi kami, takala kami dapat hadir rutin setiap tiga bulan sekali untuk saling bertukar pikiran mengenai hal-hal baru dibidang sosial, ekonomi dan bisnis.

Pada kesempatan ini penerbit menyampaikan terima kasih kepada semua pihak yang telah mengirimkan artikel-artikelnya. Penerbit akan membuka kesempatan seluas-luasnya bagi seluruh kalangan akademisi maupun praktisi baik dari dalam maupun luar Universitas Semarang untuk mempublikasikan karya ilmiahnya.

Penerbitan majalah ilmiah "SOLUSI" kali ini menghadirkan 15 (Lima Belas) artikel yang kami anggap layak untuk diterbitkan, dengan harapan dapat menjadi tambahan referensi bagi para pembaca dan menjadi sumbangan pengembangan persemaian khasanah pengetahuan dibidang sosial, ekonomi dan bisnis.

Akhir kata semoga majalah ilmiah "SOLUSI" dapat memberi manfaat yang sebesar-besarnya.

Hormat Kami 


\section{DAFTAR ISI}

PENGARUH WORK FAMILY CONFLICT, STRES KERJA DAN KEPEMIMPINAN TERHADAP TURNOVER INTENTION KARYAWAN (STUDI PADA SELURUH KARYAWAN BAGIAN PLANNING PRODUCTION AND INVENTORY CONTROL PT. PARKLAND WORLD INDONESIA JEPARA)

(Ferani; Kesi Widjajanti - Universitas Semarang)

STUDI SOFT SKILL LULUSAN PENDIDIKAN KEJURUAN DI TEMPAT KERJA

(Albert - Universitas Semarang)...

ANALISIS LINGKUNGAN INTERNAL DAN EKSTERNAL PADA UKM PREMIUM PLUS

LAUNDRY CABANG MULAWARMAN SEMARANG

(Nur Fitriani; Eviatiwi Kusumaningtyas Sugiyanto - Universitas Semarang)

FAKTOR-FAKTOR YANG MEMPENGARUHI PERTIMBANGAN TINGKAT

MATERIALITAS AUDIT

(Nita Andriyani; Dianing Ratna Wijayani; Sri Mulyani - Universitas Muria Kudus).

MANAJEMEN LABA DAN FAKTOR-FAKTOR YANG MEMPENGARUHINYA

(STUDI EMPIRIS PADA PERUSAHAN MANUFAKTUR DI BEI)

(Utami; Ardiani Ika Sulistyawati - Universitas Semarang)

PENDAPATAN ASLI DAERAH, DANA PERIMBANGAN, DAN SISA LEBIH PEMBIAYAAN ANGGARAN TERHADAP PENGALOKASIAN BELANJA MODAL: STUDI PADA

KABUPATEN/KOTA DI PROVINSI JAWA TENGAH

(Saifudin; Eka Ayu Siswanti - Universitas Semarang).

PERSEPSI PENGGUNA JASA TRANS JATENG TERHADAP KUALITAS PELAYANAN ANGKUTAN AGLOMERASI PERKOTAAN TRANS JATENG

(Studi Kasus Trans Jateng Koridor I Semarang (Tawang) - Bawen)

(Rr. Citra Aristi Amelia; Edy Mulyantomo; Sugeng Rianto - Universitas Semarang)

WORTHLESSNESS IS A POWER: MENGAPA ORANG BERSEDIA MENARUH UANG DI APLIKASI GO-PAY

(Rahoyo; Rr. Lulus Prapti N.S.S.; Asih Niati - Universitas Semarang).

ANALISIS PENGARUH KUALITAS PRODUK, PERSEPSI HARGA, DAN PROMOSI TERHADAP KEPUTUSAN PEMBELIAN WELLBLUE ALKALINE WATER PITCHER

STRATEGI PEMASARAN UNTUK MENINGKATKAN VOLUME PENJUALAN (STUDI KASUS PADA SHOFA CATERING)

(Wiki Sulistyaningsih; Teguh Ariefiantoro; Edy Suryawardana - Universitas Semarang)

PENGARUH CITRA MEREK, PERSEPSI HARGA, DAN KUALITAS PRODUK TERHADAP KEPUTUSAN PEMBELIAN SEPATU OLAH RAGA MEREK ADIDAS

(Studi di Kota Semarang)

(Rokh Eddy Prabowo; Kis Indriyaningrum; Anggita Dian Setyani - Universitas Stikubank Semarang) .121

PENGARUH KEMUDAHAN TERHADAP KEPUTUSAN MENGGUNAKAN E-BANKING PADA BNI 46 KC KARANGAYU SEMARANG DENGAN MINAT NASABAH DAN KEPERCAYAAN SEBAGAI VARIABEL MEDIASI

(Ahmad Sahri Romadon; Risma Nurhapsari - Universitas Semarang) 
PENELITIAN KEBERLANGSUNGAN USAHA ARDANI INDONESIA SEBAGAI UMKM BERBASIS INDUSTRI KREATIF

(Soegihartono - Universitas Semarang)

STRATEGI PELAYANAN BUS RAPID TRANSIT (BRT) TRANS SEMARANG

(Susanto - Universitas Semarang).....

ANALISIS PENGARUH KEPEMIMPINAN, STRES KERJA, DAN LINGKUNGAN KERJA TERHADAP KINERJA KARYAWAN BAGIAN PRODUKSI SEWING PT. SAMWON BUSANA INDONESIA SEMARANG

(Andana Budi Tami; Sri Yuni Widowati - Universitas Semarang). 


\title{
PENELITIAN KEBERLANGSUNGAN USAHA ARDANI INDONESIA SEBAGAI UMKM BERBASIS INDUSTRI KREATIF
}

\author{
Soegihartono \\ soegi64hartono@gmail.com
}

Fakultas Ekonomi Universitas Semarang

Diterima: Agustus 2020, Disetujui: September 2020, Dipublikasikan: Oktober 2020

\begin{abstract}
Micro, small and medium enterprises (UMKM) are a form of community business. MSMEs have an important role in the economy of society and the economy of a country. From the emergence of these UMKM, the creation of jobs that can prosper the community. Ardani Indonesia as a creative industry-based UMKM with its business engaged in making bags. Ardani Indonesia has played a part in advancing the creative industry and the country's economy. Ardani Indonesia carries out creativity and innovation in each of its products and opens job opportunities for the community. This study aims: 1) To determine the supporting factors for Ardani Indonesia's business sustainability. 2) To determine the inhibiting factors of Ardani Indonesia's business continuity. 3) To find out how to maintain the perpetuity of Ardani Indonesia's business.

Data collection methods in this study are (1) observation, (2) interview (3) documentation. To test the objectivity and validity of the data using source triangulation and technical triangulation. The data analysis used is triangulation, which is a data validity checking technique that uses something other than the data for checking purposes or as a comparison.

The results of the study state: 1) Factors that support the perpetuity of Ardani Indonesia's business as a creative industry-based UMKM, including: Affordable prices make consumers buy, good product quality, products that meet consumer needs, marketing well done, having good service towards consumers. 2) Factors that hamper the sustainability of Ardani Indonesia's business as a Creative Industry-based UMKM, among others: Little capital, Lack of effective social networks in promotion, less massive marketing, Still relying on other brands in its business, Rarely creating new products. 3) Ways to Maintain Ardani Indonesia's Business as a Creative Industrybased UMKM, among others: Increase production capacity, Add product models to attract consumers, Conduct more massive promotions, Participate in MSME activities to add social networks and increase knowledge, Open new stores in the area strategic, maintain product quality so that consumers are loyal.
\end{abstract}

Keywords: Permanence, Ardani Indonesia, Small Industry 


\begin{abstract}
ABSTRAK
Usaha mikro, kecil dan menengah (UMKM) merupakan bentuk usaha masyarakat. UMKM mempunyai peranan penting dalam perekonomian masyarakat dan perekonomian suatu Negara. Dari munculnya UMKM ini terciptanya lapangan kerja yang bisa mensejahterahkan masyarakat. Ardani Indonesia sebagai UMKM berbasis industri kreatif dengan usahanya bergerak di bidang pembuatan tas. Ardani Indonesia memiliki andil dalam memajukan industri kreatif dan perekonomian Negara. Ardani Indonesia melakukan kreativitas dan inovasi pada setiap produknya serta membuka lapangan kerja bagi masyarakat Penelitian ini bertujuan: 1) Untuk mengetahui faktor pendukung kelanggengan usaha Ardani Indonesia. 2) Untuk mengetahui faktor penghambat kelanggengan usaha Ardani Indonesia. 3) Untuk mengetahui cara mempertahankan kelanggengan usaha Ardani Indonesia.

Metode pengumpulan data dalam penelitian ini yaitu (1) observasi, (2) wawancara (3) dokumentasi. Untuk menguji objektivitas dan keabsahan data menggunakan triangulasi sumber dan triangulasi teknik. Analisis data yang digunakan adalah triangulasi merupakan teknik pemeriksaan keabsahan data yang memanfaatkan sesuatu yang lain di luar data itu untuk keperluan pengecekan atau sebagai pembanding.

Hasil penelitian menyatakan : 1) Faktor-Faktor yang Mendukung Kelanggengan Usaha Ardani Indonesia sebagai UMKM berbasis Industri Kreatif antara lain : Harga yang terjangkau membuat konsumen membeli, Kualitas produk yang bagus, Produk yang sesuai kebutuhan konsumen, Pemasaran yang dilakukan dengan baik, Memiliki pelayanan baik terhadap konsumen. 2) Faktor yang Menghambat Kelanggengan Usaha Ardani Indonesia sebagai UMKM berbasis Industri Kreatif antara lain : Permodalan yang sedikit, Kurangnya jejaring sosial yang efektif dalam promosi, Pemasaran yang kurang massif, Masih mengandalkan merk lain dalam berusahanya, Jarang menciptakan produk baru. 3) Cara Mempertahankan Usaha Ardani Indonesia sebagai UMKM berbasis Industri Kreatif antara lain : Menambah kapasitas produksi, Menambah model produk untuk menarik konsumen, Melakukan promosi yang lebih massif, Mengikuti kegiatan-kegiatan UMKM untuk menambah jejaring sosial dan menambah pengetahuan, Membuka toko baru di daerah yang strategis, Menjaga kualitas produk agar konsumen setia.
\end{abstract}

Kata Kunci: Kelanggengan, Ardani Indonesia, Industri Kecil

\title{
PENDAHULUAN
}

Usaha mikro, kecil dan menengah (UMKM) merupakan bentuk usaha masyarakat. UMKM mempunyai peranan penting dalam perekonomian masyarakat dan perekonomian suatu Negara. Dari munculnya UMKM ini terciptanya lapangan kerja yang bisa mensejahterahkan masyarakat.Industri kreatif merupakan sebuah kegiatan usaha yang berfokus pada kreativitas dan inovasi.Industri kreatif dapat memberikan kontribusi perekonomian suatu Negara. Yang dimana terciptanya lapangan kerja, menggerakkanmotivasi dan kreativitas masyarakat dan berdampak pada kehidupan social masyarakat.

Dengan perkembangan zaman dan teknologi yang terus maju dan pesat. UMKM berbasis industri kreatif harus memiliki kreativitas dan inovasi dalam produknya untuk bisa bertahan di kompetisi yang ketat saat ini. Tidak hanya melakukan kreativitas dan inovasi, UMKM berbasis industri kreatif juga harus memiliki kompetensi disetiap 
produknya. Dengan memiliki kompetensi para pengusaha ini dapat mempermudah pengembangan usahanya.

Ardani Indonesia sebagai UMKM berbasis industri kreatif dengan usahanya bergerak di bidang pembuatan tas. Ardani Indonesia memiliki andil dalam memajukan industri kreatif dan perekonomian Negara. Ardani Indonesia melakukan kreativitas dan inovasi pada setiap produknya serta membuka lapangan kerja bagi masyarakat. Ardani Indonesia yang melakukan usaha ini sudah 18 tahun. Merupakan hal yang sangat sulit untuk mencapai 18 tahun berusaha sebagai UMKM berbasis industri kreatif. Dulu Ardani Indonesia adalah sebuah indutri rumahan yang belum banyak hal yang dilakukan Ardani Indonesia yaitu melakukan inovasi dan kreativitas dalam produknya. Dan tidak hanya itu, Ardani Indonesia memiliki kompetensi dalam hal usaha pembuatan tas yang membuat bertahan sampai sekarang ini. Serta keuletan yang dilakukan Ardani Indonesia yang membuat Ardani Indonesia masih bisa bertahan dari persaingan UMKM.

\section{LANDASAN TEORI}

\section{Pengertian UMKM dan Ekonomi Kreatif}

Usaha mikro kecil merupakan kegiatan ekonomi rakyat yang berskala kecil dengan bidang usaha yang secara mayoritas merupakan kegiatan usaha kecil. Menurut Keputusan Presiden RI no. 99 tahun 1998 pengertian Usaha Kecil adalah: "Kegiatan ekonomi rakyat yang berskala kecil dengan bidang usaha yang secara mayoritas merupakan kegiatan usaha kecil dan perlu dilindungi untuk mencegah dari persaingan usaha yang tidak sehat."

Industri kreatif merupakan sebuah kegiatan usaha yang berfokus padsa kreativitas dan inovasi. Menurut Departemen Perdagangan RI (2009:5), Industri Kreatif adalah Industri yang berasal dari pemanfaatan kreativitas, keterampilan serta bakat individu untuk menciptakan kesejahteraan dan lapangan kerja dengan menghasilkan dan memberdayakan daya kreasi dan daya cipta individu. Simatupang (2008, h.69) juga menjelaskan bahwa industri kreatif adalah industry yang mengandalkan talenta, ketrampilan, dan kreativitas yang merupakan elemen dasar setiap individu.

\section{Kompetensi Kewirausahaan}

Kompetensi kewirausahaan diartikan Enrepreneurial competency is defined as the individual characteristic. Entrepreneur is a person who undertakes risk for gaining profit in the business venture (Kaur \& Bains, 2013 dalam (Kurniawan \& Yun, 2018)). Cason and Gudley dalam (Dimitriades, Zoe S, 2007 dalam (Kurniawan \& Yun, 2018)) menjelaskan kompetensi kewirausahaan berasal dari orientasi strategis dari perusahaan. Menurut Lado, et all dalam (Saba Khalid dan Khalid Bhatti, 2015 dalam (Kurniawan \& Yun, 2018). Define entrepreneurialcompetence as the managerial capability of a firm's leader to create and communicate a strategic vision for structuring inter-firm relation. Kompetensi kewirausahaan merupakan visi strategi dalam membangun sebuah hubungan internal di perusahaan.

\section{Perilaku Kewirausahaan}

Teori perilaku dalam Fadiati (2011), menyatakan perilaku kewirausahaan seseorang adalah hasil dari sebuah kerja yang bertumpu pada konsep dan teori 
bukan karena sifat kepribadian seorang atau berdasarkan intuisi. Seorang wirausahawan individu mempunyai ciri dan watak untuk berprestasi lebih tinggi dari kebanyakan individu - individu lainnya.

\section{Kelanggengan Usaha}

Seorang pengusaha menginginkan usahanya atau bisnisnya bisa bertahan lama. Kelanggengan usaha atau bisnis terletak pada keberlanjutan eksistensi sebuah organisasi di pasar relevan yang dilayani oleh suatu perusahaan (Banbury \& Mitchell, 1995). Ada tiga alasan mengapa kelanggengan bisnis dijadikan kriteria kinerja dalam berwiarausaha. Pertama, survival merupakan ukuran minimum kesuksesan perusahaan atau bisnis dan prasyaratnbagi indikator kinerja bisnis lainnya seperti pertumbuhan, profitabilitas, pangsa pasar dan lain lain. Kedua, prinsip "going concern" dalam bisnis terutama akuntansi menyatakan sebuah organisasi bisnis didirikan dengan maksud untuk hidup selamanya (Kieso, D.E. dkk. 2010). Ketiga, fakta empiris menunjukkan terjun ke sebuah bisnis atau usaha tampaknya relative gampang namun bukanlah hal mudah untuk bertahan hidup (survive) (Geroski, 1995).

\section{Kesuksesan}

Paul G. Stolz dalam Adversity Quotient : Mengubah Hambatan Menjadi Peluang (2000) mengungkapkan, kesusksesan adalah "tingkat dimana seseorang bergerak ke depan, ke atas, terus maju dalam menjalani hidupnya, kendati terdapat berbagai rintangan atas bentuk - bentuk kesengsaraan lainnya". Menurut Mubyarto dalam Harimurti Subanar (2001) yang dikutip oleh I Nyoman Jamel bisnis yangberhasil adalah mereka yang memulai dari usaha kecil - kecilan bukannya yang sekaligus menjadi besar, yang di pentingkan adalah keuletan dan keterampilan sebagia manajer dan inovator.

\section{Keberhasilan Usaha}

Menurut Haryadi dalam Lindrayanti (2003) "Keberhasilan usaha biasanya dicirikan dengan membesarnya skala usaha yang dimilikinya. Dapat dilihat dari volume produksinya yang tadinya biasa menghabiskan sejumlah bahan baku perhari meningkat menjadi mampu mengolah bahan baku yang lebih banyak, dengan meningkatnya bahan baku yang dibutuhkan berarti meningkat pada jumlah buruhnya (baik buruh produksi maupun pemasaran) sekaligus mencarikan perluasan jaringan pemasaran”. 


\section{Alur Penelitian}

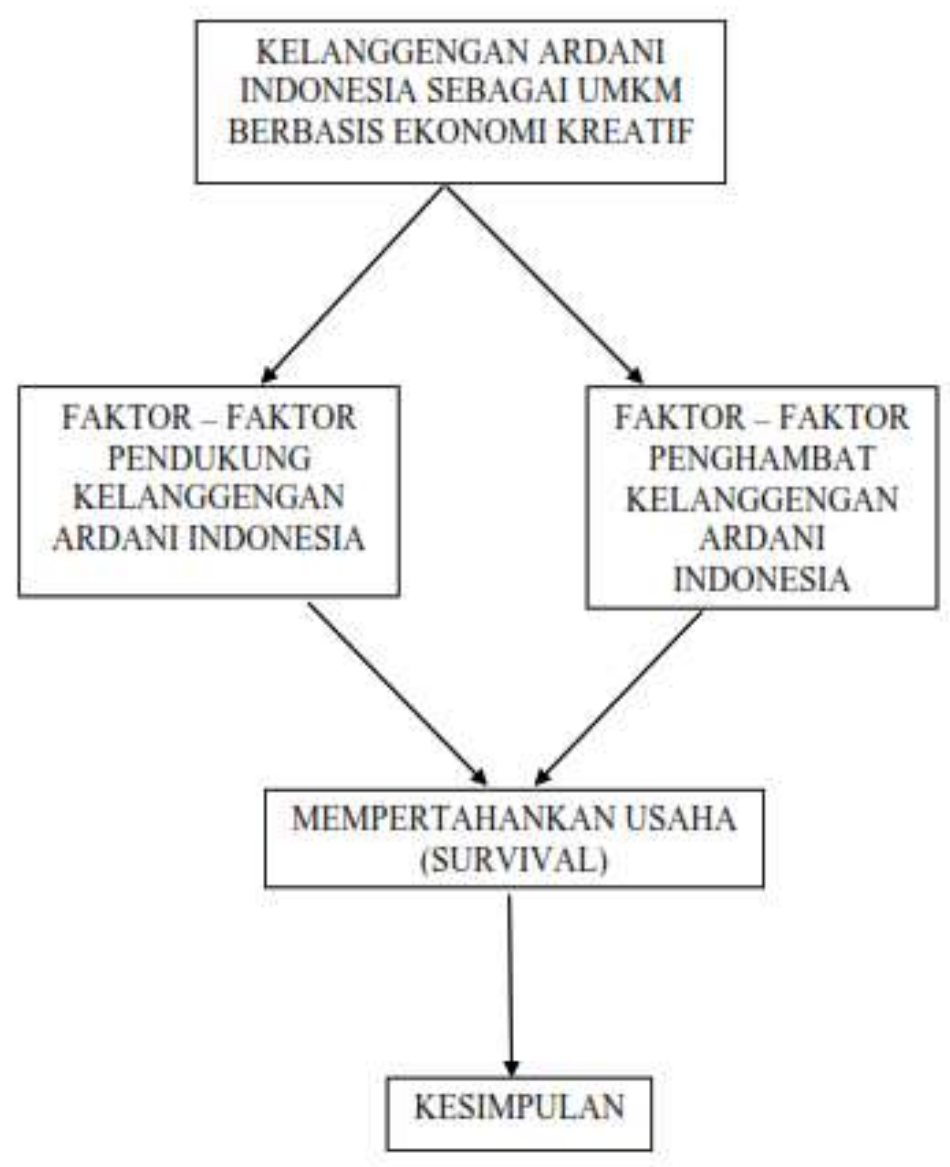

Gambar 1

\section{METODE PENELITIAN}

\section{Jenis Penelitian}

Penelitian ini, penulis menggunakan penelitian kualitatif. Menurut Sugiyono (2013) menyatakan bahwa metode penelitian kualitatif yang berlandaskan pada filsafat postpositivisme, digunakan untuk meneliti pada kondisi obyek yang alamiah, (sebagai lawanya adalah eksperimen) dimana peneliti adalah sebagai intrumen kunci, pengambilan sumber data dilakukan secara purposive, teknik pengumpulan dengan tringulasi (gabungan), analisis data bersifat induktif / kualitatif, dan hasil penelitian lebih menekankan makna dari pada generalisasi. Dalam penelitian kualitatif ini, penulis menggunakan metode atau pendekatan studi kasus (Case Study). Pendekatan studi kasus penelitian untuk memusatkan secara intensif pada satu objek sebagai suatu kasus. Menurut Yin (2013) studi kasus adalah suatu penelitianempiris yang menyelidiki fenomena di dalam konteks kehidupan nyata, bilamana batas - batas antara fenomena dan konteks tak tampak dengan tegas dan dimana multisumber digunakan. Menurut Poerwandri (2009) "Studi kasus dapat membuat penelitian memiliki pemahaman yang utuh dan terintegrasi mengenai interelasi berbagai fakta dan dimensi dari 
kasus khusus yang dikaji”.

\section{Data Penelitian}

Pohan dalam Pratowo (2016) menjelaskan data kualitatif adalah semua bahan, keterangan, fakta - fakta yang tidak dapat diukur dan di hitung secara matematis karena berwujud keterangan verbal (kalimat dan kata), selain itu data kualitatif lebih bersifat proses.

Data Primer Adalah data dari berbagai informasi dan keterangan yang diperoleh langsung dari sumber yaitu para pihak yang dijadikan informan penelitian. Jenis data ini meliputi informasi dan keterangan mengenai kelanggengan usaha. Pada penelitian ini data diperoleh dari wawancara dan observasi.

Data Sekunder adalah data yang diperoleh dari dokumentasi, jurnal / artikel / buku - buku dan epustakaan tentang penelitian ini. Pada penelitian ini data diperoleh dari laporan penjualan UMKM Ardani Indonesia dan dokumentasi yang di pereoleh selama penelitian.

\section{Tempat dan Waktu Penelitian}

Penelitian ini dilakukan di Usaha Ardani Indonesia yang beralamatkan di Jl. Sadewa 7 No. 3 Semarang. Penelitian ini dilakukan pada bulan Januari 2020 sampai dengan bulan April 2020.

\section{Subjek dan Objek Penelitian}

Menurut Idrus (2009) informan merupakan seseorang yang dapat memberikan keterangan atau informasi tertentu pada penelitian. Subjek penelitian disebut juga dengan istilah informan. Informan adalah orang yang dipercayai menjadi narasumber atau sumber informasi olehpeneliti yang akan memberikan informasi secara akurat untuk melengkapi data penelitian. Dalam penelitian ini terdapat 2 informan diantaranya, Informan kunci yaitu orang yang sangat memahami permasalahan yang diteliti. Adapun yang dimaksud sebagai informan kunci di dalam penelitian ini adalah Pemilik Ardani Indonesia, Informan non kunci / pendukung, yaitu orang yang dianggap mengetahui permasalahan yang diteliti. Adapun yang dimaksud sebagai informan non kunci / pendukung di dalam penelitian ini adalah Karyawan Ardani Indonesia, Konsumen Ardani Indonesia, Supplier Ardani Indonesia.Objek penelitian ini adalah faktor - faktor pendukung, penghambat, dan cara mempertahankan kelanggengan usaha Ardani Indonesia.

\section{Metode Pengumpulan Data}

Untuk memperoleh data yang valid penelitian ini menggunakan beberapa teknik pengumpulan data. Metode yang digunakan adalah :

Wawancara yaitu suatu percakapan yang diarahkan pada suatu masalah tertentu dan merupakan proses tanya jawab lisan dimana dua orang atau lebih berhadapan secara fisik (Setyadin dalam Gunawan, 2013). Metode wawancara yang digunakan adalah wawancara tertulis dan wawancara lisan. Tujuannya adalah untuk memperoleh informasi yang lebih detail dan mengkaji penelitian secara mendalam. 
Observasi yaitu suatu metode pengumpulan data yang dilakukan dengan cara mengadakan pengamatan dan pencatatan secara sistematis baik secara langsung maupun secara tidak langsung pada tempat yang diamati (Hadi dan Nurkancana dalam Suardeyasasri, 2010). Observasi berfungsi sebagai metode pendukung dalam penelitian dan digunakan untuk melengkapi data yang tidak dapat di dapatkan melalui metode wawancara.

Metode dokumentasi untuk melengkapi data dari wawancara dan observasi. Dokumentasi dapat berupa gambar, foto, rekaman, dan catatan lama yang berhubungan dengan penelitian.

\section{Teknik Analisis Data}

Uji Kredibilitas Data Menurut Sugiyono (2012), menyatakan bahwa uji kredibilitas data dalam penelitian kualitatif antara lain dapat dilakukkan dengan perpanjangan pengamatan, peningkatan ketekunan dalam penelitian, triangulasi, diskusi dengaan teman sejawat, analisis kasus negative, dan membercheck.

Menurut Sarosa (2017), jika peneliti hendak mengumpulkan data berupa narasi (dan narasi menjadi sumber data utama), maka peneliti harus menggali cerita dari para informan atau partisipan (Myers, 2015). Dalam melakukan wawancara, pertanyaan terbuka (open-ended questions) cocok untuk memancing para partisipan mengungkapkan cerita mereka (Riesman, 1993). Jika diteliti adalah suatu organisasi makan penelitian dapat menuliskan studi kasus, yang disitu narasi ditulis secara kronologis (Czarniawska, 1998).

\section{HASIL PENELITIAN}

1. Faktor - Faktor Yang Mendukung Kelanggengan Usaha

Berdasarkan hasil penelitian faktor-faktor yang mendukung usaha Ardani Indonesia sebagai UMKM berbasis industri kreatif antara lain, Harga, Kualitas Produk, Produk yang Sesuai Kebutuhan, Pemasaran yang baik, dan Pelayanan yang baik.

\section{Faktor - Faktor Yang Menghambat Kelanggengan Usaha}

Berdasarkan hasil penelitian faktor - faktor yang mengahmbat usahaArdani Indonesia sebagai UMKM berbasis industri kreatif antara lain, Modal, Citra Merk, Inovasi Produk, Produk yang Monoton, serta Bahan Baku.

\section{Cara Mempertahankan Usaha}

Berdasarkan hasil penelitian upaya mempertahankan usahaArdani Indonesia sebagai UMKM berbasis industri kreatif meliputi, Menambah Kapasitas Produksi, Menambah Model / Jenis Produk Sesuai Permintaan Pasar, Promosi, Mendirikan / Bergabung dalam Komunitas, Lokasi Usaha, serta Menjaga dan Meningkatkan Kualitas Produk. 


\section{PENUTUP}

\section{Kesimpulan}

Berdasarakan hasil penelitian dan pembahasan maka dapat disimpulkan hasil sebagai berikut :

a. Faktor-Faktor yang Mendukung Kelanggengan Usaha Ardani Indonesia sebagai UMKM berbasis Industri Kreatif :

1) Harga yang terjangkau membuat konsumen membeli.

2) Kualitas produk yang bagus.

3) Produk yang sesuai kebutuhan konsumen.

4) Pemasaran yang dilakukan dengan baik.

5) Memiliki pelayanan baik terhadap konsumen

b. Faktor yang Menghambat Kelanggengan Usaha Ardani Indonesia sebagai UMKM berbasis Industri Kreatif

1) Permodalan yang sedikit.

2) Kurangnya jejaring sosial yang efektif dalam promosi.

3) Pemasaran yang kurang massifmasih.

4) Mengandalkan merk lain dalam berusahanya.

5) Jarang menciptakan produk baru.

c. Cara Mempertahankan Usaha Ardani Indonesia sebagai UMKM berbasis Industri Kreatif

1) Menambah kapasitas produksi.Menambah model produk untuk menarik konsumen.

2) Melakukan promosi yang lebih massif .

3) Mengikuti kegiatan-kegiatan UMKM untuk menambah jejaring sosial dan menambah pengetahuan.

4) Membuka toko baru di lokasi yang strategis.

5) Menjaga kualitas produk agar konsumen setia.

\section{Saran}

a. Bagi pemilik Usaha Ardani Indonesia sebaiknya mengembangkan inovasi produk dengan cara membuat produk baru yang berbeda dengan produk lainnya, selain itu pelaku usaha juga sebaiknya menambah produk baru dan melakukan promosi agar konsumen sadar akan produkproduk baru yang telah dibuat, hal ini agar inovasi yang dilakukan dapat mencapai hasil yang diinginkan.

b. Bagi pemilik Usaha Ardani Indonesiasebaiknya mencari produk yang sedang diminati konsumen karena pada dasarnya pelaku usaha sebaiknya mengerti produk apa yang diinginkan oleh konsumen. Selain itu, pelaku usaha juga sebaiknya membuat produk-produk buatan sendiri serta membuat produk-produk yang lebih baik dari pesaing misalnya dengan meningkatkan kualitas produk yaitu dari bahan, desain produk yang manarik, unik dan membuat produk yang lebih rapih serta awet.

c. Bagi pemerintah diharapkan dapat memberikan kebijakan dan upayaupaya untuk meningkatkan kinerja sektor ini telah ada serta memberikan dukungan dengan meningkatkan investasi pada usaha mikro dan kecil agar lebih membantu UMKM menjadi lebih baik. 


\section{Keterbatasan Penelitian}

Adanya keterbatasan waktu dan data yang membuat penelitian ini kurang maksimal. Dan keterbatasan narasumber atau bagian pendukung lainnya yang kurang menyebabkan proses penelitian ini kurang. Variasi data maupun narasumber yang banyak dapat memperkuat kesimpulan penelitian.

\section{DAFTAR PUSTAKA}

Abduh, Thamrin. 2018. Strategi Internasionalisasi UMKM. Makasar : CV Sah Media.

Adisaputro, Gunawan. 2014. Manajemen Pemasaran (Analisis Untuk PerancanganStrategi Pemasaran). Yogyakarta: UPP STIM YKPN.

Alma, Buchari. 2013. Manajemen Pemasaran dan Pemasaran Jasa. Bandung: Alfabeta. Amstrong, Gary \& Philip, Kotler. 2002. Dasar-dasar Pemasaran. Jilid 1, Alih Bahasa

Alexander Sindoro dan Benyamin Molan. Jakarta: Penerbit Prenhalindo.

Angipora Marius P., 2002, Dasar-Dasar Pemasaran, PT. Raja Grafindo Persada,Jakarta.

Azhar Susanto, 2004. Sistem Informasi Manajemen.Bandung: Linggar Jaya.

Bambang Riyanto. 2001. Dasar-dasar Pembelanjaan Perusahaan. BPFE, Yogyakarta.

Banbury, C.M., and Mitchell, W. (1995). The Effect of Introducing Important Incremental Innovations on Market Share and Business Survival. Strategic Management Journal 16 (Special Issue: Tecnological Transformation and the Competitive Landscape), 161-182.

Basu Swastha \& Irawan. 2003. "Manajemen Pemasaran Modern”. (Edisi kedua)Cetakan ke sebelas. Yogyakarta : Liberty Offset.

Cooper, Robert G dan Elko J, Kleinschmidt. 2000. New Product Performance: What Dsitinguishes the Star Proucts. Australian Journal of Management. TheAustralian Graduate School of Management.

Departemen Perdagangan RI. 2009. "Studi Industri Kreatif Indonesia 2009”.Departemen Perdagangan Republik Indonesia. Depdag RI, 2009.

Geroski, P. A. (1995). What Do We Know About Entry. International Journal ofIndustrial Organization, 13, 421-440.

Handoko T. Hani, 2000, Manajemen Personalia dan Sumberdaya Manusia, Edisi II,Cetakan Keempat Belas, Penerbit BPFE, Yogyakarta.

Haryadi, Dedi, dkk. 2003. Tahap Perkembangan Usaha Kecil. Bandung: AKATIGA. 
Hermawan Kertajaya. 2010. Grow with Character: The Model Marketing. Jakarta: PT.Gramedia Pustaka Utama.

Husein Umar, 2009, Metode Penelitian untuk Skripsi Dan Tesis Bisnis, Edisi kedua,Rajagrafindo Persada Jakarta.

Indarti, N. (2004). Business Location and Success: The Case of Internet Café Business in Indonesia. Gadjah Mada International Journal of Business, 6, 171-192.

Kieso, D.E. et al 2010. Intermediate Accounting (13th ed.). New York: John Wiley $\&$ Sons, Inc.

Kotler, P. \& Keller, K.L. (2012), Manajemen Pemasaran Jilid I Edisi ke 12. Jakarta:Erlangga.

Kurniawan, Asep. Irawan Andri, Y. (2016). Model Kompetensi Pelaku Usaha KecilBidang Kuliner di Kota Cimahi dan Kota Bandung.Laporan PenelitianKompetitif UNJANI.

Kurniawan, Asep \& Yun Yun. 2018 Pengaruh Kompetensi Kewirausahaan danKelanggenganUsaha Terhadap Keunggulan Bersaing. Jurnal Inspirasi Bisnisdan Manajemen, Vol 2, (1), 65-78

Li, Tiger \& Calantone, Roger J. (1998). The impact of Market Knowledge Competence on New Product Advantage, Conceptualization and Empirical Examination.Journal of Marketing, Vol. 62.

Lupiyoadi, R. (2001). Manajemen Pemasaran Jasa: Teori dan Praktik. Edisi Pertama.Jakarta: Salemba Empat.

Masiyal Kholmi, 2003 ”Akuntasi Biaya", Edisi Empat, Yogyakarta, BPFE.

Nasution, M. N. (2004). Manajemen Jasa Terpadu. Bogor: Ghalia Indonesia

Prihutami, N.D. 2011. Analisis Faktor Penentu Produksi Tandan Buah Segar (TBS)Tanaman Kelapa. Jurnal EPP 6 (2): 9-15.

Rahayu, Sri Lestari, 2005, Analisis Peranan Perusahaan Modal Ventura DalamMengembangkan UKM di Indonesia.

Saladin, Djaslim, 1996, Unsur-Unsur Inti Pemasaran dan Manajemen Pemasaran,Bandung: Mandar Maju.

Schiffman \& Kanuk. 2004. Riset Perilaku Konsumen. PT. Gramedia Pustaka Utama,Jakarta.

Simatupang E.J, 2008, "Penerapan Unsur-Unsur Manajemen”, Penerbit Buku AwanIndah, Jakarta. 
Soemarso. 2005. Akuntansi Suatu Pengantar. Edisi Revisi, Jakarta: Salemba Empat.

Supranto. Limakrisna, Nandan, 2011, Perilaku Konsumen dan Strategi Pemasaran.Mitra Wacana Media: Jakarta.

Sutardi A, \& Endang Budiasih. 2007. Sediakan Dan Hitung Stock Agar TakKehilangan Konsumen, Elex Media Komputindo, Jakarta.

Tambunan, Tulus, 2012. "Usaha Mikro Kecil dan Menengah di Indonesia : isuisupenting", Jakarta : LP3ES. IsuPenting. Salemba Empat. Jakarta.

Tandjung, Jenu Widjaja. 2011. Marketing Management : Pendekatan Pada NilaiNilaiPelanggan. Edisi Kedua. Cetakan Kedua. Bayumedia Publishing. Malang.

Timmons, J.A. \& Spinelli, S. (2004). New Venture Creation. (Terjemahan JuliantoAgung Saputro). London: McGraw. (Buku asli diterbitkan tahun 2004).

Tjiptono, F. 2002. Pemasaran Jasa. Malang: Bayumedia Publishing.

Toni Wijaya. (2011). Manajemen Kualitas Jasa. Jakarta. PT INdeks.

Ulrich, Karl T. \& Steven D. Eppinger (2001) Perancangan \& Pengembangan Produk.Salemba Teknika, Jakarta.

Utaminingsih, Adijati. et al 2016, Jurnal Dinamika Sosial Budaya, Volume 18, Nomor2.

Yuyun Wirasasmita (1994). Kewirausahaan : Buku Pegangan Jatinangor : UPTPenerbitanIKOPIN.

Zimmer, T.W. \& Scarborough, N.M., 1996. Essentials of Entrepreneurship and Small Busines.

1996. Entrepreneurship and New Jersey: Prentice Hall International Inc. hal 51. 